\title{
GALVANIKK KOROZYON VE ALÜMİNYUM-BAKIR ÜZERİNE DENEYSEL BİR ÇALIŞMA
}

\author{
Tansel KOYUN*, Şevki Yılmaz GÜVEN
}

Süleyman Demirel Üniversitesi, Mühendislik Fakültesi, Makina Mühendisliği Bölümü, Isparta, Türkiye

Anahtar Kelimeler
Korozyon,
Bakır boru,
Alüminyum boru,
Galvanik korozyon,

\begin{abstract}
Özet
Korozyon, endüstride ve insan sağlığı açısından önem arz eden besin maddeleri muhafazası kadar ısıtma, soğutma ve iklimlendirme sistemlerinde de karşımıza çıkmaktadır. Akışkan hareketi olan, olmayan ve özellikle de yoğuşma ve buharlaşma olan borularda zamanla korozyon oluşmaktadır. Bazı metaller korozyona uğrama konusunda daha aktiftirler. İklimlendirme sistemlerinde boru malzemesi olarak korozyona uğrama konusunda daha az aktif olan bakır kullanılmaktadır. Bu çalışmada, korozyon konusunda daha aktif olan alüminyum ve daha az aktif olan bakır birlikte bir deney setinde ele alınarak oluşan korozyon ve bu malzemelerin nasıl etkilendiği incelenmiştir. İlk olarak bakır ve alüminyum metaller arasındaki potansiyel fark, (volt) cinsinden ölçülmüştür. Daha sonra tasarlanan sistemde anot-katot reaksiyonları oluşturularak sistemde korozyon artış miktarı ve ardından oluşan bu korozyonu azaltmak için farklı bir tasarım yapılmıştır. Yeni tasarlanan sistem deneysel olarak incelenmiş ve korozyondaki azalmanın miktarı gözlenmiştir.
\end{abstract}

\section{AN EXPERIMENTAL STUDY ON GALVANIC CORROSION AND ALUMINUM- COPPER}

\begin{tabular}{ll}
\hline Keywords & Abstract \\
\hline $\begin{array}{l}\text { Corrosion }, \\
\text { Copper pipe, }\end{array}$ & Corrosion is important in refrigeration, heating and air conditioning systems, as well as \\
Aluminum pipe, & in industry and in preserving foods which are important for human health. Regardless of \\
Galvanic corrosion,, & the fluid motion, corrosion is formed over time in pipes in which especially condensation \\
and evaporation occur. Some metals are more active in exposure to corrosion. In air \\
conditioning systems, copper which is less active in exposure to corrosion is used as pipe \\
material. In this study, aluminum (more active than copper to corrosion) and copper \\
pipes were used on an experimental set up to investigate how these materials are affected \\
by the corrosion. First, the voltage values between aluminum and copper metals were \\
measured in volts. Then the anode-cathode reactions in the system designed were \\
formed and the increase in the amount of corrosion was measured. A different design has \\
been made to reduce the resulting corrosion. The new designed system has been \\
analyzed experimentally and the amount of reduction in corrosion was observed.
\end{tabular}

Alıntı / Cite

Koyun, T., Güven, Ş. Y. (2017). An Experimental Study On Galvanic Corrosion And Aluminum-Copper, Journal of Engineering Sciences and Design, 5(1), 331-335.

\section{Giriş}

Korozyon doğal bir olaydır. Doğal olarak gerçekleşen tüm reaksiyonların sonucunda oluşan yapılar daha kararlıdır. Yapının kararlılığı ise özelliklerini kaybeden metal veya alaşımların sahip olduğu enerjisindeki düşmeye entropisindeki yükselmeye bağlıdır. Aslında bütün doğal olayların açıklanmasında enerji ve entropi gibi kavramların kullanılması bizim sonuçları doğru yorumlayabilmemiz için önemlidir. Korozyon, metallerin veya alaşımların sahip olduğu özelliklerini kaybederek doğada daha kararlı bir hale geçmesi olayıdır, kısaca çevrenin etkisiyle malzemenin parçalanması ve kullanılamaz hale gelmesidir (Erbil, 1984; Gerengi, 2012; Şamandar ve Gerengi, 2009).

\footnotetext{
* ilgili yazar/Corresponding Author:: tanselkoyun@sdu.edu.tr, +90-246-211-1237
} 
Korozyon olayında kimyasal ve elektrokimyasal olaylar gerçekleşmektedir. Bu olaylar doğal bir olay olduğu için teorik derslerde görülen anodik ve katodik bölgeler de doğal olarak oluşmaktadır. Korozyon olayı anot ve katotta karşılıklı meydana gelen reaksiyonlar sonucu gerçekleşmektedir. Anotta yükseltgenme reaksiyonu ile metal, iyon haline geçer. Bu durumda açığa çıkan elektron metal üzerinde kalır. Korozyon olayının devam edebilmesi için açı̆̆a çıkan elektronların bir şekilde katoda taşınması gerekmektedir. Eğer anotta toplanan elektronlar taşınmiyorsa, anot reaksiyonu kısa bir süre sonra dengeye erişerek durur. Eğer, elektron alışverişi olursa korozyon devam eder (Şamandar ve Gerengi, 2009)

Korozyonun hayatımızdaki önemi, ekonomik açıdan; tahribata uğramış bir metalin tekrar kullanılabilir bir hale dönüștürülebilmesi, güvenlik açısından; korozyon nedeni ile metalin zayıflaması, görevini yerine getiremeyecek duruma gelmesi ve ciddi kazalara neden olması, kaynakların korunması açısından; ileriye dönük olarak stokların oluşturulması şeklinde genel hatları ile açıklanabilir (Konuklu, 2007).

Korozyon, insan sağlığı bakımından da oldukça önemlidir. Özellikle, korozyon ürünlerinin, besin maddeleri ve ilaçların içine sızması tehlikeli sonuçlar doğurabilmektedir. Endüstride ise, açlk atmosferde bulunan tanklar, depolar, direkler, taşıtlar, iş makineleri, metal aksamdan yapılmış binalar, yeraltı boru hatları, gemiler, iskele ayakları vb. her şey korozyon süreci ile karşı karşıyadır. Korozyon sonucu dayanımını yitirmiş yapıtların, beklenmedik bir zamanda çökmesi iş kazalarına neden olur. Korozyon nedeniyle boşa giden harcamalar, üretim giderlerini de arttırmaktadır. İngiltere'de korozyon ve korozyonun neden olduğu ekonomik kaybın, yıllık 1365 milyon pound olduğu tahmin edilmektedir. Bunun için bilim adamları, korozyon hızının ölçülmesi ve korozyondan korunma önlemlerinin alınabilmesi için sürekli araștırmalar yapmaktadır. Elde edilen veriler doğrultusunda yeni alaşımlar veya istenildiği takdirde korozyon sürecine müdahaleler söz konusu olmaktadır (Gerengi vd., 2012; Gerengi, 2008)

\section{Bilimsel Yazın Taraması}

Yapılan çalışma ile ilgili bilimsel araştırmalar incelendiğinde, oluşan korozyonu önlemek adına farklı çalışmalar yapıldığı görülmüştür.

Metalik parçaların korozyondan korunması veya korozyonun yavaşlatılması için çeşitli önlemler alınmaktadır. Korozyonu önlemek için metalin bulunduğu ortam ile etkileşmesini engellemek gerekmektedir. Bunun en genel yolu, metal üzerinde bir film oluşturmak veya metali kaplamaktır. Asan vd. (tarih) tarafından yapılan çalışmada, 304 çeliğinin polipirolle kaplanması ve bu kaplamanın asidik, tuzlu ve bazik ortamlardaki korozyondan koruma etkinliğinin araştırılması amaçlanmıştır (Asan vd., 2008).

Mekanik tesisatların verimini düșüren ve ömrünü önemli derecede azaltan en önemli faktörlerden biri olan korozyon, mühendislikte amaçlanan minimum maliyetle maksimum verimin sağlanması amacını her azaman olumsuz yönde etkiler. Korozyonun tamamının engellenmesi hiçbir zaman mümkün değildir. Mekanik tesisatlarda tasarım aşamasından itibaren korozyon olayı göz önünde bulundurulmalı ve tesisatın devreye alınmasından sonra da izlenmelidir. Kıncay vd.(2011) yaptıkları çalışmada, buhar kazanlarının kullanıldığı ısıtma tesisatlarında korozyon koruma programının nasıl uygulanıp kontrol edilmesi gerektiğini açıllayarak ilgili ölçütlerin hesapları ile birlikte örnekler vermişlerdir. Baynal vd. (2012) yaptıkları çalışmada, klasik deney tasarım metoduyla ortodontik uygulamalarda yaygın bir şekilde kullanılan NiTi, $\beta$-Ti ve FeCrNi alaşımlarının flor ve asit katkılı Fusuyama çözeltisi içerisinde 14 ve 28 günlük etkileşimleri sonrasındaki korozyon davranışları analiz ederek, varyans analizi ve hipotez testleri ile parametreler arası etkileşimleri irdeleyip ve grafikler halinde ifade etmişlerdir. Kurt ve Başyiğit (2015), yaptıkları çalışmada; dubleks paslanmaz çeliklerde ısıl işlem ve kaynak uygulaması veya kullanım ömrü süresince değișen termal koşullara göre mikro yapıda oluşabilecek zararlı fazlardan olan sigma fazının tespit edilmesi ve korozyon davranışlarına etkilerinin incelenmesi amaçlamışlardır.

$\mathrm{Bu}$ durumda, bir çok uygulamada karşımıza çıkan korozyonun azaltılmasına yönelik çalışmaların yapılması önem arz etmektedir.

\section{Deneysel Çalışma}

Bu çalışmada, daha aktif olan alüminyum, daha az aktif olan bakır ile birlikte bir deney setinde ele alınarak bu malzemelerin korozyondan nasıl etkilendiğini incelemek ve korozyonu azaltmak amacıyla iki farklı deney yapılmıştır.

Deneylerde, elektrik iletkenliğine sahip (elektrolit) çözelti olan tesisat su ortamında iki farklı metal arasında oluşan gerilim farkı etkisiyle galvanik birim oluşmaktadır. Çalışmada kullanılan suyun pH değeri 7.2 olarak ölçülmüştür. Elektrot potansiyel gerilimi düşük olan metal, elektrolit içinde çözünerek korozyon sürecini başlatmaktadır.

Şekil 1. de Alüminyumda korozyon oluşumunu gerçekleștirmek için çıplak bakır boru ve alüminyum boruların birbirlerine bağlanmış şekli gösterilmektedir. 


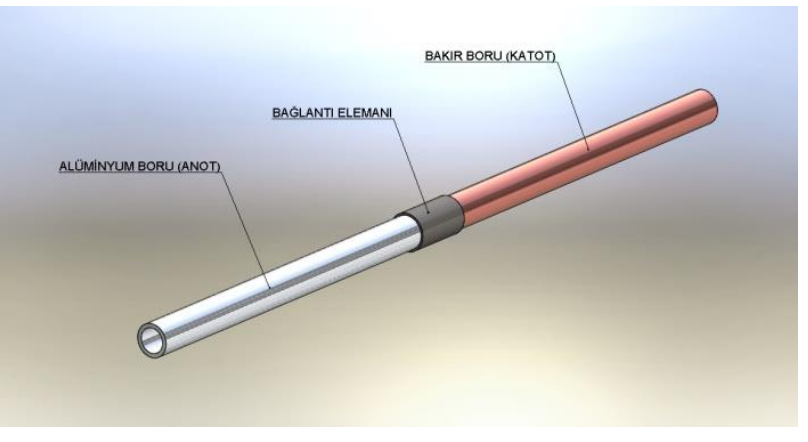

Şekil 1. Aluminyum ve bakır boru bağlantısı

Şekil 2 de prototip olarak oluşturulan deney seti görülmektedir.

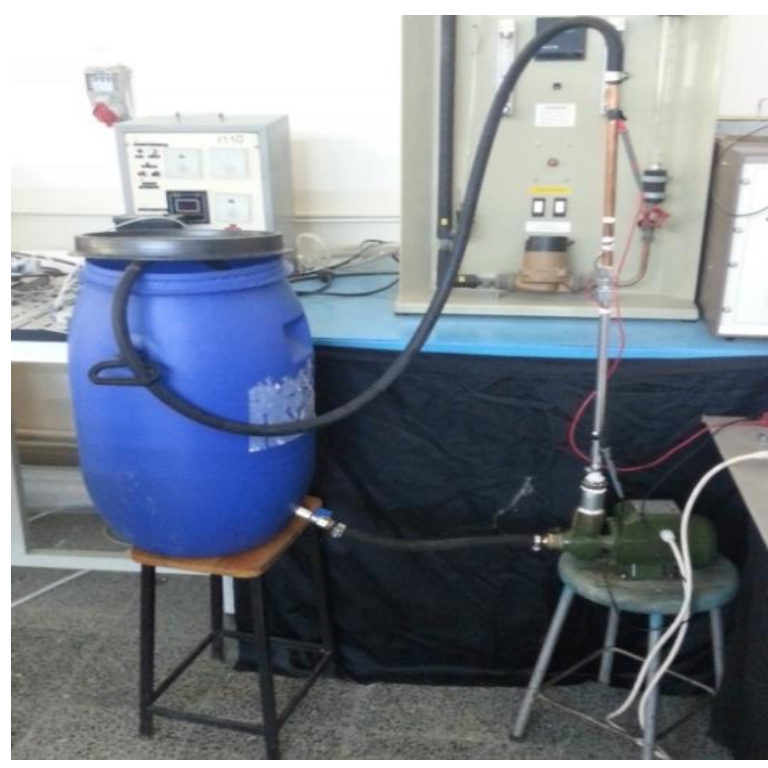

Şekil 2. Korozyon deney seti (1. Deney)

Birinci deneyde amacımız, çıplak bakır boru ve alüminyum boruların birbirlerine bir yalıtkan nipel ile bağlanmaları sonucunda alüminyumda meydana gelen korozyonun hızını ölçmek ve yapacağımız ikinci deney için karşılaştırma değerlerini elde etmek olmuștur.

$\mathrm{Bu}$ amaçla $12 \mathrm{~mm}$ iç çap, $16 \mathrm{~mm}$ diş çap ve $40 \mathrm{~cm}$ uzunluğa sahip birer tane bakır ve alüminyum boru kullanılmıştır. Borular birbirlerine yalıtkan bir nipel yardımıyla sızdırmazlık sağlanacak șekilde bağlanmıș, sonra bakır borunun diğer ucuna dayanıklı ve esnek su hortumu geçirilmiş, 13-19 mm'lik kelepçe ile sıkılarak tekrar sızdırmazlık sağlanmıștır. Tüm bu bağlantılar yapıldıktan sonra hortum vasitasıyla suyun tanka girişi sağlanmıștır. Suyun devir daimi için ise,, küçük çaplı bahçe sulamalarında, yazlık ve villalarda hidrofor pompası olarak kullanılan MUR-CELL PKM60 elektrikli su pompası seçilmiştir. Kullanılacak suyu depolamak için metal bir su tankı kullanmak yerine alüminyumun korozyon hızına etki edeceğinden plastik bir bidon kullanılmasına karar verilmiştir. 40 litre hacmindeki mavi plastik bidonun alt kısmına küresel vana bağlanmıștır. Bidondan pompaya su geçişini sağlamak amacıyla ise vana çıkışı ile pompanın girişi arasına siyah esnek su hortumu kelepçeler ile bağlanmış ve böylelikle pompa için gerekli su sağlanmıștır. Alüminyumda meydana gelen galvanik korozyonu ölçmek için, ölçüm cihazı olarak VICHY - VC8045 dijital multimetre kullanılmıștır.

Gerekli kontroller yapıldıktan sonra pompa çalıştırılmış ve üç gün beklendikten sonra ölçüm alınmaya başlanmıştır. Multimetrenin ayarı DC $2 \mathrm{~V}^{\prime} \mathrm{da}$ iken propların uçlarının biri bakır boruya diğeri ise alüminyum boruya bağlanarak hafta sonları hariç toplam 7 gün ölçüm alınmıştır. Ölçüm yapılan günlerin tarihi, hava sıcaklığı ve multimetrede okunan volt cinsinden değerler aşağıda Tablo 1' de verilmiștir. $\mathrm{Bu}$ deneyde aldığımız değerler, ikinci deneydeki değerlerle karşılaştırmada kullanılacaktır.

Tablo 1. Birinci Deneyin Ölçüm Değerleri

\begin{tabular}{|c|c|c|c|}
\hline GÜN & TARIH & SICAKLIK & $\begin{array}{c}\text { ÖLÇÜLEN DEĞER } \\
\text { (V) }\end{array}$ \\
\hline 1 & 21.04.2015 & $21^{\circ} \mathrm{C}$ & $0,021 \mathrm{~V}$ \\
\hline 2 & 22.04 .2015 & $19^{\circ} \mathrm{C}$ & $0,023 \mathrm{~V}$ \\
\hline 3 & 24.04 .2015 & $19^{\circ} \mathrm{C}$ & $0,028 \mathrm{~V}$ \\
\hline 4 & 27.04.2015 & $23^{\circ} \mathrm{C}$ & $0,036 \mathrm{~V}$ \\
\hline 5 & 28.04.2015 & $24^{\circ} \mathrm{C}$ & $0,041 \mathrm{~V}$ \\
\hline 6 & 29.04.2015 & $23^{\circ} \mathrm{C}$ & $0,045 \mathrm{~V}$ \\
\hline 7 & 30.04 .2015 & $26^{\circ} \mathrm{C}$ & $0,051 \mathrm{~V}$ \\
\hline
\end{tabular}

Ölçülen değerlerden de görüldüğü üzere, potansiyel farkı ne kadar yüksekse galvanik korozyon riski o kadar yükselir. Çünkü aradaki potansiyel farkının büyüklüğü anotta meydana gelen korozyon hızının bir göstergesidir. Voltaj ne kadar yüksek ise, korozyon şiddeti o kadar yüksektir. Aynı şekilde sıcaklık yükseldikçe korozyon reaksiyon hızı da yükselmektedir. Ancak bu çalışmada sıcaklığın korozyon üzerindeki etkisi ihmal edilmiştir. Galvanik korozyonun etkilerini azaltmak için:

* Eğer farklı metallerin birleştirilmesi kaçınılmaz ise galvanik seride birbirine daha yakın olanlar seçilmelidir.

* Anot katot yüzey oranlarını hesaba katılmalı; mümkün olduğunda daha geniş bir anot yüzeyi tercih edilmelidir.

* Farklı metalleri elektriksel olarak birbirinden yalıtmaya çalışılmalıdır. 
* Üçüncü anodik bir metali elektriksel olarak diğer ikisine bağlanmalıdır. (bir çeşit katodik koruma)

$\mathrm{Bu}$ çalışmada yapılan ikinci deneydeki amaç, alüminyumda meydana gelen korozyon hızını yavaşlatmak için yeni bir tasarım ile, bunun etkilerini görmek olmuştur. $\mathrm{Bu}$ amaçla, birinci deneyde kullanılan borularla aynı özelliklere sahip bakır ve alüminyum yeni borular kullanılmıştır. Alüminyum boru üzerine matkapla $6 \mathrm{~mm}$ çapında çift taraflı beş delik açılmış, çinko levhaların monte edileceği yerlere sızdırmazlık amaciyla teflon bant sarılmıştır. $\mathrm{Bu}$ işlemlerden sonra çinko levhalar kelepçe yardımıyla deliklerin üzerine sabitlenmiştir. Elektron akışını sağlamak için üç metale de (bakır, alüminyum, çinko) temas edecek şekilde bakır tel sarılmıștır. Birinci deneyin sona erdiği gün ikinci deney hazırlanıp pompa çalıştırılmış ve birinci deneyde olduğu gibi üç gün beklendikten sonra ölçüm alınmaya başlanmıştır. Multimetrenin ayarı DC 2V'da iken propların uçlarının biri bakır boruya diğeri ise alüminyum boruya bağlanarak hafta sonları hariç toplam 7 gün ölçüm yapılmış. Ölçümlerden elde edilen değerler birinci deneyimizdeki değerlerle karşılaştırılmak üzere not edilmiştir.

Ölçüm yapılan günlerin tarihi, hava sıcaklığı ve multimetrede okunan volt cinsinden değerler aşağıda Tablo 2' de verilmiştir.

Tablo 2. İkinci Deneyin Ölçüm Değerleri

\begin{tabular}{|c|c|c|c|}
\hline GÜN & TARIH & $\begin{array}{c}\text { HAVA } \\
\text { SICAKLIĞI }\end{array}$ & ÖLÇÜLEN DEĞER (V) \\
\hline 1 & 04.05 .2015 & $27^{\circ} \mathrm{C}$ & $0,016 \mathrm{~V}$ \\
\hline 2 & 05.05 .2015 & $27^{\circ} \mathrm{C}$ & $0,017 \mathrm{~V}$ \\
\hline 3 & 06.05 .2015 & $30^{\circ} \mathrm{C}$ & $0,019 \mathrm{~V}$ \\
\hline 4 & 07.05.2015 & $27^{\circ} \mathrm{C}$ & $0,020 \mathrm{~V}$ \\
\hline 5 & 08.05 .2015 & $25^{\circ} \mathrm{C}$ & $0,022 \mathrm{~V}$ \\
\hline 6 & 11.05 .2015 & $21^{\circ} \mathrm{C}$ & $0,026 \mathrm{~V}$ \\
\hline 7 & 12.05 .2015 & $25^{\circ} \mathrm{C}$ & $0,028 \mathrm{~V}$ \\
\hline
\end{tabular}

Şekil 3 de. Korozyonu azaltmak üzere tasarlanan deney seti görülmektedir.

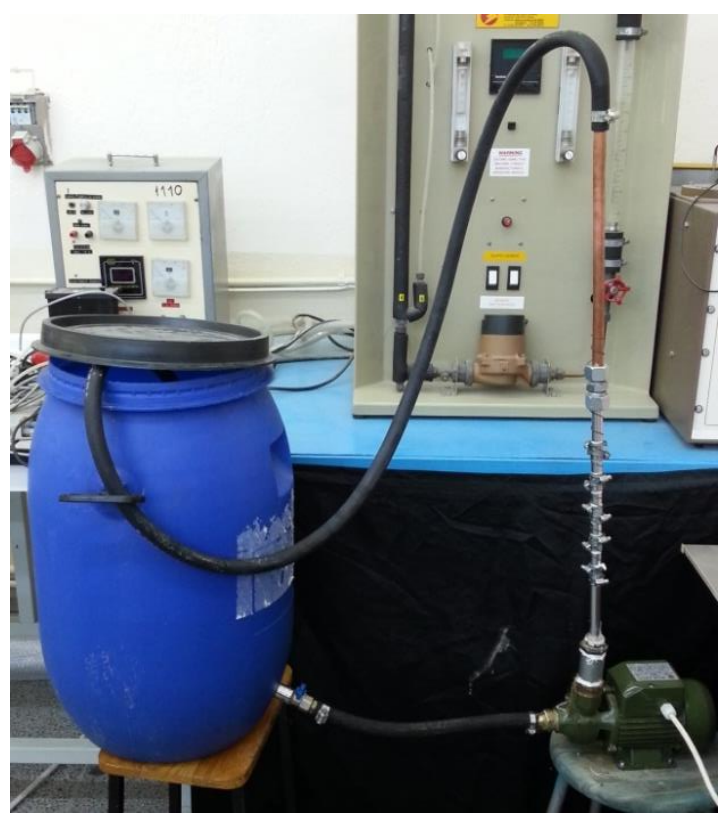

Şekil 3. Korozyon deney seti (2. Deney)

\section{Araştırma Bulguları}

Şekil 4.'de de görüldüğü üzere ikinci deneyde elde ettiğimiz değerler birinci deneyde elde edilen değerlerle karşılaştırıldığında, korozyon hızının birinci deneyde daha hızlı bir şekilde artış gösterdiği görülmüştür. Sonuç olarak ikinci deneyde kullanılan tasarımın, alüminyum borudaki korozyon hızını azalttığını görülmüștür.

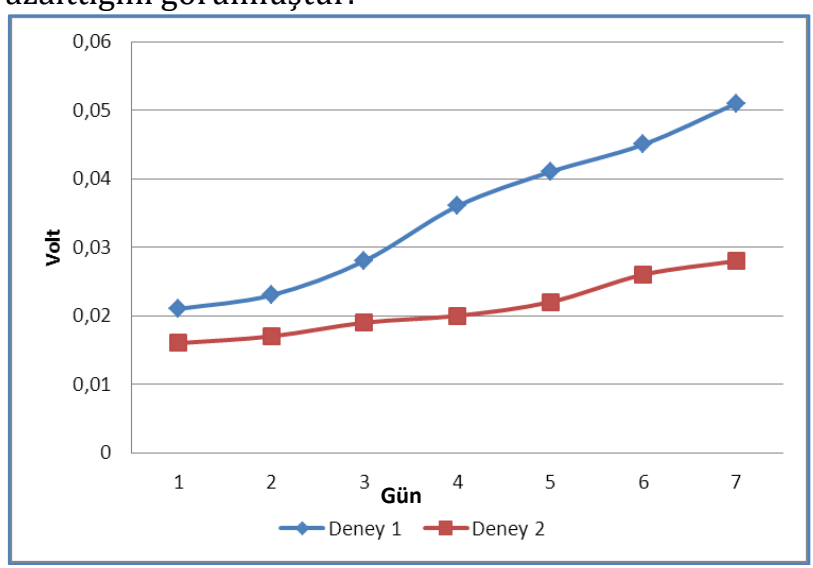

Şekil 4. Korozyon hızının değişimi

\section{Sonuç ve Tartışma}

Çalışmamızda bakır ve alüminyum boru bağlantılarındaki korozyon (galvanik korozyon) sorunu ele alınmış ve bu sorunun azaltılmasına yönelik yeni bir tasarım ile deneyler yapılmıştır. Korozyon hızını azaltmaya yönelik bakır tel sarılı tasarımın, çinko metalinin elektrot potansiyeli değerinin (-0.76 Volt), Alüminyum metalinin elektrot potansiyeli değerinden ( -1.67 Volt) düşük olmasına 
rağmen (İnternet-I, 2017) korozyon hızını azalttı̆̆ı görülmüștür.

$\mathrm{Bu}$ çalışmada, iki adet deney gerçekleştirilmiş, ilk deneyde sadece bakır ve alüminyum boru kullanılarak multimetre ile potansiyel fark ölçümü yapılmış, ikinci deneyde ise, bu iki metale ilave olarak çinko metali kullanılmış ve her üç metale (bakır-alüminyumçinko) temas edecek şekilde bakır tel sarılmıştır. Bakır tel sarılı yeni tasarım için ölçümler yapılmıştır(2. deney). Ölçümler sonucunda birinci deneyde bakır ve alüminyum arasındaki potansiyel farkın, ikinci deneye kıyasla daha hızlı artış gösterdiği görülmüştür. Korozyonu azaltmaya yönelik tasarımda bakır tel ve çinko kullanımının elektron akışı üzerine olumlu etkisinin olduğu ve böylece korozyon hızını azalttığı sonucuna varılmıştır.

Ayrıca, çalışmanın, metalleri korozyondan koruma üzerine ileride yapılacak olan çalışmalara ışık tutacağı düşünülmektedir.

\section{Conflict of Interest / Çıkar Çatışması}

Yazarlar tarafından herhangi bir çıkar çatışması beyan edilmemiştir.

No conflict of interest was declared by the authors.

\section{Kaynaklar}

Asan, A., Aslan B., Korkmaz Ö., 2008. Polipirolle Korozyondan Korunma, XI. International Corrosion Symposium, 600-605, İzmir.

Başyiğit A.B., Kurt A., 2015. Dubleks Paslanmaz Çeliklerde Sigma Fazının Korozyon Dayanımına Etkileri, nternational Journal of Engineering Researchand Development, Vol.7, No.4, 2015, Savunma Sanayi Sempozyumu Özel Sayısı.

Baynal K., Altuğ, G.S., Ünal, H.İ., 2012. Ortodontik Tellerin Korozyon Davranışının Klasik Deney Tasarım Yöntemi ile Belirlenmesi, TMMOB MMO Mühendis ve Makina Dergisi, cilt 53, sayı 629, s. 4854.

Erbil, M., 1984. Korozyon İnhibitörleri, SEGEM, Ankara.

Gerengi, H., 2008, Tafel Polarizasyon (TP), Lineer polarizasyon (LP), Harmonik Analiz (HA) ve Dinamik Elektrokimyasal impedans Spektroskopisi (DEIS) Yöntemleriyle Düşük Karbon Çeliği (AISI 1026), Pirinç-MM55 ve Nikalium-118 Alaşımlarının Yapay Deniz Suyunda Korozyon Davranışları ve Pirinç Alaşımlarına
Benzotriazol'un İnhibitör Etkisinin Araştırılması, Doktora Tezi, Eskişehir Osmangazi Üniversitesi.

Gerengi, H. Şamandar A., 2009. Gerengi, H. ve Şamandar, A., 2009, The necessity of corrosion technology program, I. Uluslar arası 5. Ulusal Meslek Yüksek Okulları Sempozyumu, 27-29 Mayıs Konya, 318-319.

Gerengi, H., 2012. Anticorrosive Properties of Date Palm (Phoenix dactylifera L.) Fruit Juice on 7075 Type Aluminum Alloy in 3.5\% NaCl Solution, Ind. Eng.Chem.Res., 51(39), pp12835-12843.

Gerengi, H., Özgan E., Akçay, Ç., Arslan, İ., 2012. Asfalt Betonu İçerisine Konulan Düsük Karbon Çeliğinin \%3,5 $\mathrm{NaCl}$ Ortamindaki Korozyonunun İncelenmesi, Mehmet Akif Ersoy Üniversitesi Fen Bilimleri Enstitüsü Dergisi, 3(1), 5-11.

İnternet- I, http://hyperphysics.phyastr.gsu.edu/hbase/Chemical/electrode.html (Erişim Tarihi: 08.02.2017)

Kıncay, O., Öztop M., Ağustos H., 2010. Buhar kazan ve Tesisatlarında Korozyon Koruma Programı Deneysel Uygulama, Tmmob Tesisat Mühendisliği, 50-60, Yıl: 16, sayı: 120.

Konuklu, S., 2007. Alüminyum Yüzeyindeki Oksit Tabakasının Sülfürik Asit Anodizing Yöntemiyle Geliştirilmesi, Çukurova Üniversitesi Fen Bilimleri Enstitüsü, Adana. 